\title{
Exigência de Proteína Digestível para Larvas de Tilápia do Nilo (Oreochromis niloticus), durante a Reversão Sexual
}

\author{
Carmino Hayashi ${ }^{1}$, Wilson Rogério Boscolo ${ }^{2}$, Claudemir Martins Soares ${ }^{3}$, Fábio Meurer ${ }^{4}$
}

\begin{abstract}
RESUMO - O principal objetivo deste trabalho foi determinar a exigência de proteína digestível (PD) para a tilápia do Nilo na fase de reversão sexual, onde foram utilizadas 1250 larvas distribuídas em 25 aquários (60L), com cinco tratamentos e cinco repetições em um delineamento inteiramente casualizado. As larvas foram alimentadas com rações isoenergéticas, isocálcicas e isofosfóricas, contendo 30, 34, 38, 42 e 46\% de PD e 30 mg/kg do hormônio a-metil testosterona. O arraçoamento foi realizado à vontade, cinco vezes ao dia. Os animais de cada unidade experimental foram contados e pesados aos 15 e aos 28 dias de experimento para avaliação da sobrevivência e do peso médio. Para o peso médio dos animais, observou-se efeito quadrático, com ponto de máximo de 39,06 e 38,56\% de PD aos 15 e 28 dias, respectivamente. A sobrevivência diminuiu linearmente com o aumento nos níveis de PD, aos 15 e 28 dias. A temperatura da água, o pH, a condutividade e o nível de oxigênio dissolvido apresentaram valores médios de 24,60 $\pm 2,02^{\circ} \mathrm{C} ; 7,34 \pm 0,22 ; 218,47 \pm$ $16,29 \mu \mathrm{S} / \mathrm{cm}$ e $6,38 \pm 1,18 \mathrm{mg} / \mathrm{L}$ respectivamente. A exigência de PD para a tilápia do Nilo determinada para a fase de reversão sexual foi de $38,6 \%$.
\end{abstract}

Palavras-chave: exigência de proteína, fase larval, Oreochromis niloticus, tilápia do Nilo

\section{Digestible Protein Requirement for Nile Tilapia Larvae (Oreochromis niloticus) during the Sexual Reversion}

\begin{abstract}
The aim of the work was to determine the digestible protein requirement (PD) for Nile tilapia in the sexual reversion phase, where 1250 larvae were assigned to 25 aquariums $(60 \mathrm{~L}$ ), with five treatments and five replicates in a completly randomized design. The larvae were fed ad libitum, five times a day, with isoenergy, isocalcium, isophophorus rations, with 30, 34, 38, 42 and 46\% of PD, and $30 \mathrm{mg} / \mathrm{kg}$ of a-metil hormone testosterone. The animals of each experimental unit were counted and weighed at each 15 and 28 days of experiment for evaluation of the survival and average weight. For the average weight of the animals quadratic effect was observed, with point of maximum of 39.06 and $38.56 \%$ of PD at 15 and 28 days, respectively. The survival rate linearly decreased as the PD levels increased, at 15 and 28 days. Water temperature, $\mathrm{pH}$, conductivity and dissolved oxygen level presented average values of 24.60 of \pm $2.02^{\circ} \mathrm{C} ; 7.34 \pm 0.22 ; 218.47 \pm 16.29 \mu \mathrm{S} / \mathrm{cm} ;$ and $6.38 \pm 1,18 \mathrm{mg} / \mathrm{L}$ respectively. The PD requirement of for Nile tilapia in the sexual reversion phase was of $38.6 \%$.
\end{abstract}

Key Words: protein requirement, larval phase, Nile tilapia, Oreochromis niloticus

\section{Introdução}

As tilápias constituem-se o segundo grupo de peixes de maior importância na aquicultura mundial (Lovshin, 1998), sendo de baixo nível trófico (onívora) e destacam-se em cultivos por apresentar crescimento rápido, rusticidade (Hayashi et al., 1999), além de carne de excelente qualidade com boa aceitação no mercado consumidor, sendo a mais apropriada para a indústria de filetagem, tornando-a uma espécie de grande interesse para a piscicultura.
A etapa da larvicultura é de fundamental importância para obtenção de animais em quantidade e de qualidade, pois a nutrição adequada nesta fase exerce grande influência, sendo pré-requisito básico para o sucesso nas fases subseqüentes de cultivo.

As proteínas correspondem aos nutrientes de máxima importância, pois são os componentes constituintes do organismo animal em crescimento e o perfil aminoacídico é decisivo para a sua qualidade e determina seu valor como componente da dieta (Pezzato, 1999). A alimentação é respon-

\footnotetext{
${ }^{1}$ Professor Titular do Departamento de Biologia/Universidade Estadual de Maringá. E.mail: chayashi@uem.br

2 Professor Assistente do Curso de Engenharia de Pesca/Universidade Estadual do Oeste do Paraná - Toledo - Doutorando do Programa de Pós-Graduação em Zootecnia/UEM. E.mail: wrboscolo@bol.com.br

${ }^{3}$ Programa de Pós-graduação em Ecologia de Ambientes Aquáticos Continentais-PEA, Departamento de Biologia/UEM. E.mail: cmsoares@uem.br

${ }^{4}$ Programa de Pós-Graduação em Zootecnia/UEM Av. Colombo, 5790, CEP 87020.900, Jd. Universitário, Maringá-Paraná. E.mail: f-meurer@bol.com.br
} 
sável pela maior parte do custo de produção na tilapicultura, sendo que a fração alimentar mais onerosa é sem dúvida a protéica. Este fato se deve principalmente aos altos níveis de proteína bruta (PB) utilizados nas rações, principalmente na fase inicial. Para que não sejam fornecidos níveis excessivos desse nutriente, torna-se de fundamental importância determinar as exigências protéicas dos animais para cada fase de criação (Furuya et al., 1996), para formulação de uma ração bem balanceada e de menor custo (Shiau \& Lan, 1996).

O nível de proteína em dietas para a tilápia afeta diretamente o desempenho (El-Sayed \& Teshima, 1992; Viola et al., 1994; Furuya et al. 1996; Al-Hafedh et al. 1999; Al-Hafedh, 1999), as características reprodutivas como maturação sexual e fecundidade (Gunasekera et al., 1996; Siddiqui et al., 1998; Al-Hafedh, 1999), a composição corporal em termos de percentagem de gordura e proteína (AlHafedh, 1999) e também a composição dos ovos (Gunasekera et al., 1996).

El-Sayed \& Teshima (1992) recomendam para larvas de tilápia do Nilo um nível de $45 \%$ de PB. Al-Hafedh et al. (1999), indicam para alevinos de 0,51g um nível de $40 \%$ de PB, enquanto para animais acima de 96g, rações com 30\% de PB. Já Furuya et al. (1996), avaliando níveis de PB para alevinos de tilápia do Nilo com pesos inicial e final médios de 0,44 a 38,50 g, observaram melhor desempenho dos animais alimentados com rações contendo $32,71 \%$ de PB.

É de fundamental importância o fornecimento de ração com adequado teor de proteína digestível e balanço aminoacídico, pois a porção protéica que não for digerida e absorvida será excretada. O suprimento dietário de proteína é um dos principais fatores que influenciam a produtividade dos peixes e a produção de resíduos nitrogenados que são excretados na água (Tibbetts et al., 2000), que pode resultar em redução no desempenho dos animais e poluição do ambiente de criação e dos corpos d'água que receberem os efluentes. Segundo Mires et al. (1990), verifica-se atualmente que a principal fonte de poluição em sistemas intensivos de cultivo de peixes é proveniente do fornecimento de alimentos ricos em proteína.

O objetivo do presente trabalho foi determinar a exigência de proteína digestível para larvas de tilápia do Nilo (Oreochromis niloticus), durante a fase de reversão sexual.

R. Bras. Zootec., v.31, n.2, p.823-828, 2002 (suplemento)

\section{Material e Métodos}

O experimento foi conduzido no Laboratório de Aqüicultura do Departamento de Biologia da Universidade Estadual de Maringá, no período de 20 de novembro a 18 de dezembro de 1999 . Foram utilizados 1250 larvas com dois a três dias de vida obtidas por coleta manual em viveiros de reprodução com matrizes de tilápia do Nilo.

As larvas foram distribuídas em um delineamento inteiramente casualizado com cinco tratamentos e cinco repetições, em 25 aquários com capacidade para $60 \mathrm{~L}$ dotados de aeração constante por meio de pedras microporosas conectadas a um compressor de ar. O sistema de aquecimento foi composto por aquecedores individuais de 100 watts com termostato acoplado. A unidade experimental foi considerada como sendo um aquário com 50 larvas. As rações foram formuladas com 30, 34, 38, 42 e $46 \%$ de PD nas rações, correspondendo a 32,$70 ; 37,00 ; 41,30 ; 45,70$ e $50,00 \%$ de PB (Tabela 1) sendo as mesmas isoenergéticas $(4000 \mathrm{kcal} / \mathrm{kg})$, isocálcicas e isofosfóricas (Tabela 2).

$\mathrm{O}$ arraçoamento foi realizado à vontade, cinco vezes ao dia (8h30,10h30,13h30, 15h30 e 17h30). Para confecção das rações, os alimentos foram moídos em um moinho tipo faca com peneira de 0,5 mm (Hayashi et al., 1999), misturados sendo adicionados $30 \mathrm{mg} / \mathrm{kg}$ do hormônio a-metil testosterona às rações, conforme metodologia descrita por Hayashi (1995).

Diariamente foi realizada a sifonagem do fundo dos aquários às 8 e $17 \mathrm{~h}$, antes da primeira e da última alimentação, respectivamente, substituindo-se cerca de $20 \%$ do volume total de água por vez.

Os parâmetros químicos da água, como $\mathrm{pH}$, condutividade e oxigênio dissolvido, foram medidos semanalmente, enquanto que a temperatura da água foi monitorada diariamente às $8 \mathrm{e} 17 \mathrm{~h}$.

Aos 15 dias e ao final do período experimental, os animais de cada unidade experimental foram contados e pesados para avaliação da sobrevivência e do peso final médio.

Os dados obtidos foram submetidos a análise de variância a $5 \%$ de probabilidade, em caso de diferenças aplicou-se análise de regressão através do programa estatístico SAEG (Sistema de Análise Estatística e Genética) descrito por Euclydes (1983). 
Tabela 1 - Composição percentual e química dos ingredientes nas rações experimentais, com base na matéria natural ${ }^{1}$ Table 1 - Percent and chemical ingredients composition of the experimental diets, as fed basis ${ }^{1}$

\begin{tabular}{|c|c|c|c|c|c|}
\hline \multirow[t]{2}{*}{$\begin{array}{l}\text { Alimentos }(\%) \\
\text { Foods }(\%)\end{array}$} & \multicolumn{5}{|c|}{$\begin{array}{c}\text { Proteína digestível }(\%)^{3} \\
\text { Digestible protein }\end{array}$} \\
\hline & 30,00 & 34,00 & 38,00 & 42,00 & 46,00 \\
\hline $\begin{array}{l}\text { Milho } \\
\text { Corn }\end{array}$ & 36,24 & 29,18 & 22,12 & 15,06 & 8,00 \\
\hline $\begin{array}{l}\text { Farinha de peixe } \\
\text { Fish meal }\end{array}$ & 19,97 & 22,53 & 25,01 & 27,64 & 30,20 \\
\hline $\begin{array}{l}\text { Farinha de vísceras } \\
\text { By-products poultry meal }\end{array}$ & 18,85 & 21,26 & 23,67 & 26,09 & 28,50 \\
\hline $\begin{array}{l}\text { Farelo de soja } \\
\text { Soybean meal }\end{array}$ & 13,68 & 17,94 & 22,21 & 26,47 & 30,73 \\
\hline $\begin{array}{l}\text { Óleo de soja } \\
\text { Soybean oil }\end{array}$ & 7,12 & 5,85 & 4,59 & 3,32 & 2,05 \\
\hline $\begin{array}{l}\text { Calcário calcítico } \\
\text { Limestone }\end{array}$ & 1,09 & 0,82 & 0,55 & 0,27 & - \\
\hline $\begin{array}{l}\text { Fosfato bicálcico } \\
\text { Dicalcium phosphate }\end{array}$ & 2,53 & 1,90 & 1,27 & 0,63 & - \\
\hline $\begin{array}{l}\text { Antioxidante (BHT) } \\
\text { Antioxidant }(B H T)\end{array}$ & 0,02 & 0,02 & 0,02 & 0,02 & 0,02 \\
\hline $\begin{array}{l}\text { Suplemento min.vit. }{ }^{2} \\
\text { Min. vit. supplement }\end{array}$ & 0,50 & 0,50 & 0,50 & 0,50 & 0,50 \\
\hline Total & 100,00 & 100,00 & 100,00 & 100,00 & 100,00 \\
\hline
\end{tabular}

${ }_{1}^{1}$ Baseados nos valores de composição dos alimentos por Rostagno et al. (1994) (Based on the values of foods composition by Rostagno et al. [1994]).

${ }^{2}$ Níveis de garantia por quilograma do produto (Supremais) (Warranty levels to kilogram of product [Supremais]): Vit. A, 1.200.000UI; Vit. D 3 , 200.000 Ul; Vit. E, 12.000 mg; Vit. $K_{3}, 2.400$ mg; Vit. $B_{1}, 4.800$ mg; Vit. $B_{2}, 4.800$ mg; Vit. $B_{6}, 4.000$ mg; Vit. B $12,4.800$ mg; Ác. Fólico (Folic acid), 1.200 mg; Pantotenato Ca (Pantotenate Ca), 12.000 mg; Vit. C, 48.000 mg; Biotina (Biotin), $48 \mathrm{mg}$; Colina (Colin), $65.000 \mathrm{mg}$; Niacina (Niacin), 24.000 mg; Ferro (Iron), 10.000 mg; Cu, 6.000 mg; Mn, 4.000 mg; Zn, 6.000 mg; lodo, 20 mg; Co, 2 mg; Se, 20 mg.

Tabela 2 - Composição química das rações experimentais com diferentes níveis de proteína digestível, utilizadas para alevinos de tilápia do Nilo ${ }^{1}$

Table 2 - Chemical composition of the experimental diets with different digestible protein levels fed Nile tilapia ${ }^{1}$

\begin{tabular}{|c|c|c|c|c|c|}
\hline $\begin{array}{l}\text { Energia digestível }(\mathrm{kcal} / \mathrm{kg}) \\
\text { Digestible energy }\end{array}$ & 3967 & 3987 & 4007 & 4028 & 4048 \\
\hline $\begin{array}{l}\text { Proteína digestível (\%) } \\
\text { Digestible protein }\end{array}$ & 32,00 & 34,00 & 38,00 & 42,00 & 46,00 \\
\hline $\begin{array}{l}\text { Proteína bruta }(\%) \\
\text { Crude protein }\end{array}$ & 32,70 & 37,00 & 41,30 & 45,70 & 50,00 \\
\hline $\begin{array}{l}\text { Fibra bruta (\%) } \\
\text { Crude fiber }\end{array}$ & 1,89 & 2,03 & 2,18 & 2,33 & 2,47 \\
\hline $\begin{array}{l}\text { Gordura }(\%) \\
\text { Fat }\end{array}$ & 15,72 & 15,19 & 14,65 & 14,13 & 13,60 \\
\hline $\begin{array}{l}\text { Fósforo }(\%) \\
\text { Phosphorus }\end{array}$ & 1,52 & 1,52 & 1,52 & 1,52 & 1,52 \\
\hline $\begin{array}{l}\text { Cálcio }(\%) \\
\text { Calcium }\end{array}$ & 2,84 & 2,84 & 2,84 & 2,84 & 2,84 \\
\hline $\begin{array}{l}\text { Lisina }(\%) \\
\text { Lysine }\end{array}$ & 2,06 & 2,37 & 2,68 & 2,99 & 3,30 \\
\hline $\begin{array}{l}\text { Metionina + Cistina }(\%) \\
\text { Methionine }+ \text { Cystine }\end{array}$ & 1,37 & 1,53 & 1,68 & 1,84 & 1,99 \\
\hline
\end{tabular}

${ }_{1}^{1}$ Valores de energia e proteína digestíveis calculados com base nos coeficientes de digestibilidade propostos por Degani et al. (1997) e óleo de soja por Sintayehu et al. (1996).

1 Values of digestible energy and protein calculated based on the digestible coefficients proposed by Degani et al. (1997), and for soybean oil by Sintayehu et al. (1996). 


\section{Resultados e Discussão}

Os valores de desempenho de tilápias do Nilo alimentadas com dietas contendo diferentes níveis de proteína digestível para as mesmas, na fase de reversão sexual, estão apresentados na Tabela 3.

O peso final médio dos animais no $15^{\circ}$ dia e ao final do período experimental, 28 o dia, apresentou comportamento quadrático $(\mathrm{P}<0,05)$ em função dos níveis de PD nas rações (Figura 1), com pontos de máximo a 39,06 e 38,56\% de PD respectivamente. Este resultado está de acordo com El-Dahhar \& Lovell (1995), os quais observaram que, em peixes alimentados até a saciedade, a concentração da proteína dietética tem efeito marcante no ganho de peso.

El-Sayed \& Teshima (1992), avaliando o requerimento de energia e proteína $(3000,4000$ e 5000 kcal de energia bruta/kg de ração e 30, 35, 40, 45 e 50\% de PB) para larvas de tilápia do Nilo, indicam que a exigência de PB é de $45 \%$ e $4000 \mathrm{kcal}$ de energia bruta, este resultado está de acordo com o presente trabalho, considerando que a digestibilidade da proteína bruta de alimentos convencionais para a tilápia do Nilo é em torno de 80-90\% (Hanley, 1987; Degani et al., 1997). Furuya et al. (1996), avaliando níveis de proteína bruta para alevinos de tilápia do Nilo com pesos inicial e final médios de 0,44 a 38,50 g, respectivamente, também observaram efeito quadrático sobre o ganho de peso, com ponto de máximo em $32,71 \%$ de proteína bruta.

A taxa de sobrevivência dos animais apresentou efeito linear $(\mathrm{P}<0,05)$, diminuindo com o aumento nos níveis de $\mathrm{PD}$, tanto nos primeiros 15 dias como no período total (Figura 2). Este resultado discorda de Al-Hafedh (1999), que observou aumento na sobrevivência dos animais alimentados com rações contendo níveis maiores de proteína.

Esta redução observada na sobrevivência dos animais pode ser devido ao aumento na excreção de resíduos nitrogenados pelos animais alimentados com as rações contendo os maiores níveis de proteína (Mires et al., 1990; Tibbetts et al., 2000), uma vez que a renovação de água foi a mesma para todos os tratamentos.

$\mathrm{O}$ balanço entre a energia e o requerimento de proteína para o crescimento é de grande importância para se obter uma dieta desejável (El-Dahhar \& Lovell, 1995; Taboada et al., 1998). No presente estudo a relação entre a PD e energia digestível (ED) encontrada para o melhor peso final dos animais foi de $105 \mathrm{mg}$ de PD/kcal de ED. Esta relação é semelhante a obtida por El-Sayed et al. (1992) para larvas,

Tabela 3 - Valores médios de desempenho de tilápias do Nilo alimentadas contendo rações com diferentes níveis de proteína digestível durante o período de reversão sexual

Table 3 - Performance average values of Nile tilapia during sexual reversion fed diets with different digestible protein levels

\begin{tabular}{|c|c|c|c|c|c|}
\hline \multirow[b]{2}{*}{$\begin{array}{l}\text { Variáveis } \\
\text { Variables }\end{array}$} & \multicolumn{5}{|c|}{$\begin{array}{c}\text { Proteína digestível (\%) } \\
\text { Digestible protein }\end{array}$} \\
\hline & 30 & 34 & 38 & 42 & 46 \\
\hline & \multicolumn{5}{|c|}{15 dias (15 days) } \\
\hline Peso final $(\mathrm{g})^{1}$ & 0,092 & 0,101 & 0,132 & 0,111 & 0,101 \\
\hline $\begin{array}{l}\text { Final weight } \\
\text { Sobrevivência }(\%)^{2} \\
\text { Survival rate }\end{array}$ & 93,600 & 93,000 & 94,00 & 91,500 & 89,500 \\
\hline & \multicolumn{5}{|c|}{28 dias (28 days) } \\
\hline $\begin{array}{l}\text { Peso final }(\mathrm{g})^{3} \\
\text { Final weight }\end{array}$ & 0,192 & 0,219 & 0,273 & 0,244 & 0,201 \\
\hline $\begin{array}{l}\text { Sobrevivência }(\%)^{4} \\
\text { Survival rate }\end{array}$ & 85,600 & 87,000 & 84,000 & 80,500 & 78,500 \\
\hline
\end{tabular}

1 Efeito quadrático $Y=-0,3930+0,0261 X-0,0003 X^{2} ; R^{2}=0,71$.

2 Efeito linear (sobrevivência) $=15$ dias $Y=101,1310-0,2374 X) ; R^{2}=0,79$.

3 Efeito quadrático $Y=-1,0796+0,0690 X-0,0009 X^{2}, R^{2}=0,86$.

${ }^{4}$ Efeito linear (sobrevivência) 28 dias $=Y 101,970-0,5006 X ; R^{2}=0,86$.

1 Quadratic effect $Y=-.3930+.0261 X-.0003 X^{2} ; R^{2}=.71$

2 Linear effect (survival rate) $Y=101.1310-.2374 X), R^{2}=.79$

${ }^{3}$ Quadratic effect $Y=-1.0796+.0690 X-.0009 X^{2}, R^{2}=.86$.

4 Linear effect (survival rate) 28 dias $=Y=101.970-.5006 X ; R^{2}=.86$.

R. Bras. Zootec., v.31, n.2, p.823-828, 2002 (suplemento) 


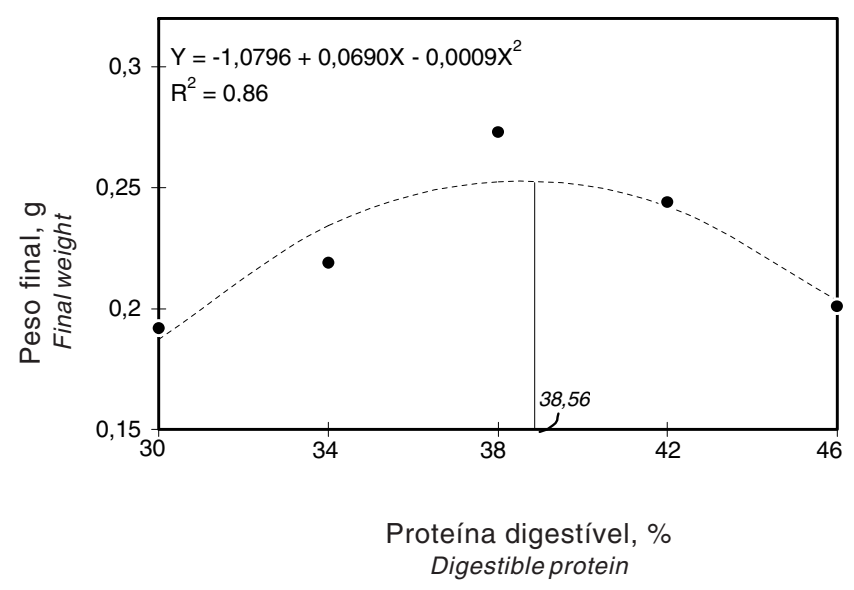

Figura 1 - Peso final de larvas de tilápia do Nilo submetidas a diferentes níveis de proteína digestível durante a fase de reversão sexual.

Figure 1 - Final weight of Nile tilapia larvae in reversion phase fed diets with different protein levels.

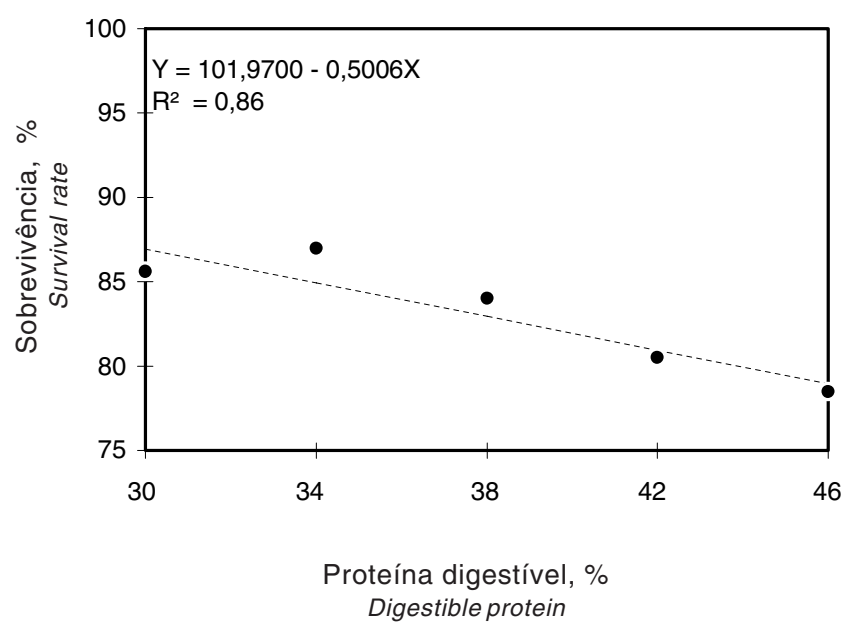

Figura 2 - Sobrevivência de larvas de tilapia do Nilo submetidas a diferentes níveis de proteína digestível durante a fase de reversão sexual.

Figure 2 - Nile tilapia larvae survival in reversion phase fed diets with different digestible protein levels.

NRC (1993) para juvenis, e El-Dahhar \& Lovell (1995) para alevinos de tilápia do Nilo.

A temperatura da água, $\mathrm{pH}$, condutividade elétrica e oxigênio dissolvido apresentaram valores médios de $24,60 \pm 2,02^{\circ} \mathrm{C} ; 7,34 \pm 0,22 ; 218,47 \pm 16,29 \mu \mathrm{S} / \mathrm{cm} \mathrm{e}$ $6,38 \pm 1,18 \mathrm{mg} / \mathrm{L}$, respectivamente, permanecendo dentro da faixa recomendada para a aquicultura (Boyd, 1990; Sipaúba-Tavares, 1995).

\section{R. Bras. Zootec., v.31, n.2, p.823-828, 2002 (suplemento)}

\section{Conclusões}

A exigência de proteína digestível para a tilápia do Nilo na fase de reversão sexual, constituída, nesta pesquisa, de 28 dias de desenvolvimento inicial, foi de $38,6 \%$.

\section{Literatura Citada}

AL-HAFEDH, Y.S. Effects of dietary protein on growth and body composition of Nile tilapia, Oreochromis niloticus L. Aquaculture Research, v.30. n.5, p.385-393, 1999.

AL-HAFEDH, Y.S.; SIDDIQUI, A.Q.; AL-SAIADY, M.Y. Effects of dietary protein levels on gonad maturation, size and age at first maturity, fecundity and growth of Nile tilapia. Aquaculture International, v.7, n.5, p.319-332, 1999.

BOYD, C. Water quality in ponds for aquaculture. London: Birmingham Publishing, 1990. 482p.

DEGANI, G.; VIOLA, S.; YEHUDA, Y. Apparent digestibility of protein and carbohydrate in feed ingredients for adult tilapia (Oreochromis aureus X O. niloticus). The Israeli Journal of Aquaculture, v.49, n.3, p.115-123, 1997.

EL-DAHHAR, A.A.; LOVELL, R.T. Effect of protein to energy ratio in purified diets on growth performance, feed utilization and body composition of Mozambicus tilapia Oreochromis niloticus (Peters). Aquaculture Research, v.26, n.7, p.451457, 1995

EL-SAYED, A.F.M.; TESHIMA. S. Protein and energyrequirements of Nile tilapia, Oreochromis niloticus, Fry. Aquaculture, v.103, n.1, p.55-63, 1992.

EUCLYDES, R.F. Manual de utilização do programa SAEG (Sistema para Análises Estatísticas e Genética). Viçosa, MG: Universidade Federal de Viçosa, 1983.

FURUYA, W.M.; HAYASHI, C.; FURUYA, V.R.B. Exigência de proteína para machos revertidos de tilápia do Nilo (Oreochromis niloticus L.), na fase juvenil. Revista UNIMAR, v.18, n.2, p.307-319, 1996.

GUNASEKERA, R.M.; SHIM, K.F.; LAM, T.J. Effect of dietary protein level on spawning performance and amino acid composition of eggs of Nile tilapia, Oreochromis niloticus. Aquaculture, v.146, n.1-2, p.121-134, 1996.

HANLEY, F. The digestibility of foodstuffs and the effects of feeding selectivity determinations in Tilápia, (Oreochromis niloticus L). Aquaculture, v.66, n.2, p.163-179, 1987.

HAYASHI, C. Breves considerações sobre as tilápias In: RIBEIRO, R.P.; HAYASHI, C.; FURUYA, W.M. (Eds.) Curso de piscicultura-criação racional de tilápias. Maringá: FADEC/UEM, 1995. p.4.

HAYASHI, C.; BOSCOLO, W.R.; SOARES, C.M. et al. Uso de diferentes graus de moagem dos ingredientes em dietas para a tilápia-do-Nilo(Oreochromis niloticus L.) na fase de crescimento. Acta Scentiarium, v.21, n.3, p.733-737, 1999.

LOVSHIN, L.L. Red tilapia or Nile tilapia: which is the best culture fish? In: SIMPÓSIO SOBRE MANEJO E NUTRIÇÃO DE PEIXES, 1998, Piracicaba. Anais... Piracicaba: Fundação de Estudos Agrários Luiz de Queiroz, 1998. p.179-198.

MIRES, D.; AMIT, Y.; AVNIMELECH, S. et al. Water quality in a recycled intensive fish culture system under field conditions. The Israeli Journal of Aquaculture, v.42, p.110-121, 1990. 
PEZZATO, L.E. Alimentação de peixes - Relação custo e benefício. In: REUNIÃO ANUAL DA SOCIEDADE BRASILEIRA DE ZOOTECNIA, 34., 1999, Porto Alegre. Anais... Porto Alegre: Sociedade Brasileira de Zootecnia, 1999. p.109-118.

NATIONAL RESEARCH COUNCIL - NRC. Nutrient requeriments of warmwater, fishes and shellfishes: Nutrient requeriments of domestics animals. Washington, D.C.: National Academy of Sciences, 1993. 114p.

ROSTAGNO, H.S.; SILVA, D.J.; COSTA, P.M.A. et al. Composição de alimentos e exigências nutricionais de aves e suínos (Tabelas brasileiras). Viçosa, MG: Universidade Federal de Viçosa, 1994. 61p.

SHIAU, S.Y., LAN, C.W. Optimum dietary protein level and protein to energy ratio for growth of grouper (Epinephelus malabaricus). Aquaculture, v.145, n.1/4, p.259-266, 1996.

SIDDIQUI, A.Q.; AL-HAFEDH, Y.S.; ALI, S.A. Effect of protein level on the reproductive performance of Nile tilapia Oreochromis niloticus (L). Aquaculture Research, v.29, n.5, p.349-358, 1998.

SINTAYEHU, A.; MATHIES, E.; MEYER-BURFDORFF, K.H. Apparent digestibilities and growth experiment with tilapia (Oreochromis niloticus) fed soybean meal, cottonseed meal and sunflower seed meal. Journal of Applied Ichthyology, v.12, n.2, p.125-130, 1996.
SIPAÚBA-TAVARES, L.H.S. Limnologia aplicada à aquicultura. Jaboticabal: Fundação Universidade Estadual Paulista, 1995. 72p.

TABOADA, G.; GAXIOLA, G.; GARCIA, T. et al. Oxygen consumption and ammonia-N excretion related to protein requirements for growth of white shrimp Penaeus setiferus (L.) juvenilis. Aquaculture Research, v.29, n.11, p.823833, 1998

TIBBETTS, S.M.; CALL, S.P.; ANDERSON, D.M. Dietary protein requirement of juvenile American eel (Anguilla rostrata) fed pratical diets. Aquaculture, v.186, n.1/2, p.145-155, 2000.

VIOLA, S.; ANGEONI, H.; GUR, N. et al. Growth-performance, protein and energy balances of hybrid tilapia fed 2 levels of lysine at 3 levels of protein. The Israeli Journal of Aquaculture, v.46, n.4, p.212-222, 1994.

Recebido em: 26/09/00

Aceito em: 21/12/01 